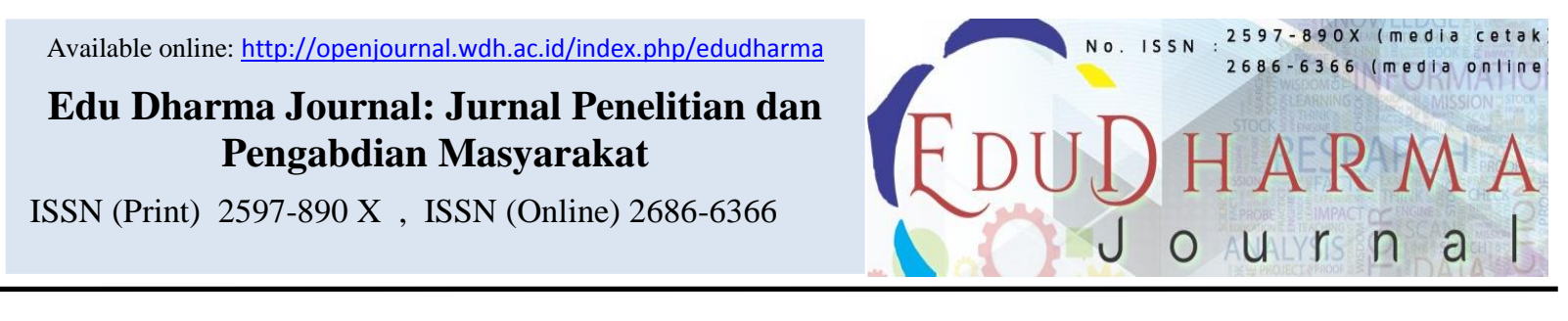

\title{
HUBUNGAN TINGKAT PENGETAUAN KESEHATAN REPRODUKSI DENGAN PERILAKU SEKSUAL REMAJA PADA SISWA SISWI DI SMK SASMITA JAYA 1 PAMULANG
}

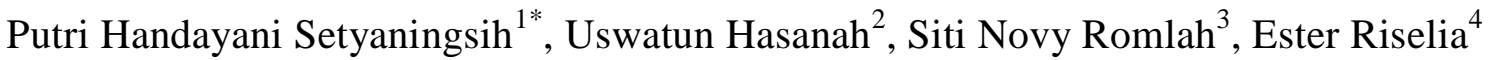 \\ STIKes Widya Dharma Husada Tangerang, J1. Pajajaran No. 1 Pamulang, Tangerang Selatan 15417, Indonesia
}

\begin{tabular}{|c|c|}
\hline ARTICLE INFORMATION & $A B S T R A C T$ \\
\hline $\begin{array}{l}\text { *Corresponding Author } \\
\text { Name } \\
\text { E-mail : putri_yupi_87@yahoo.com }\end{array}$ & $\begin{array}{l}\text { Sexual behavior problems are closely related to } \\
\text { adolescents. Adolescent sexual behavior generally starts } \\
\text { from autoerotic behavior (autoerotic behavior), where this } \\
\text { behavior starts from curiosity and enjoy the sexual } \\
\text { experience alone which can influence adolescent sexual }\end{array}$ \\
\hline $\begin{array}{l}\quad \text { Keywords: } \\
\text { Level of Knowledge_1 } \\
\text { Reproductive health_2 } \\
\text { Adolescent sexual behavior_3 }\end{array}$ & $\begin{array}{l}\text { one of the factors that can affect adolescent sexual } \\
\text { behavior. The purpose of this study was to determine the } \\
\text { relationship of reproductive health knowledge levels with } \\
\text { adolescent sexual behavior in Sasmita Jaya } 1 \text { Pamulang } \\
\text { vocational high school students. Research Methods The } \\
\text { type of research used is quantitative research with a } \\
\text { descriptive analytic research plan with a cross-sectional } \\
\text { approach. In this study the tool used in this study is to use } \\
\text { a closed questionnaire appendix, to determine the } \\
\text { relationship between the independent variable and the } \\
\text { dependent variable. The sampling technique in this study } \\
\text { is the Probability Sampling sample technique. The sample } \\
\text { in this study amounted to } 84 \text { students. Research Results } \\
\text { Statistical test results using the Chi-Square test obtained } \\
\text { p-value = } 0.053>\alpha=0.05 \text {. So it can be concluded that } \\
\text { there is no relationship between the level of reproductive } \\
\text { health knowledge with adolescent sexual behavior in } \\
\text { Sasmita Jaya } 1 \text { Pamulang vocational high school students. } \\
\text { From this research it is hoped that it can expand } \\
\text { information about adolescent sexual behavior that is } \\
\text { influenced by the level of reproductive healthknowledge. }\end{array}$ \\
\hline $\begin{array}{l}\text { Kata Kunci: } \\
\text { Tingkat pengetahuan_1 } \\
\text { Kesehatan reproduksi_2 } \\
\text { Perilaku seksual remaja_3 }\end{array}$ & $\begin{array}{l}\text { A B S T R A K } \\
\text { Masalah perilaku seksual sangat erat kaitannya dengan } \\
\text { remaja, biasanya perilaku seksual remaja berasal dari } \\
\text { perilaku seks sendiri yang diawali dengan rasa ingin tahu } \\
\text { dan hanya menikmati pengalaman seksual yang akan } \\
\text { mempengaruhi seksual remaja. Oleh karena itu, tingkat } \\
\text { pengetahuan kesehatan reproduksi yaitu faktor yang }\end{array}$ \\
\hline
\end{tabular}




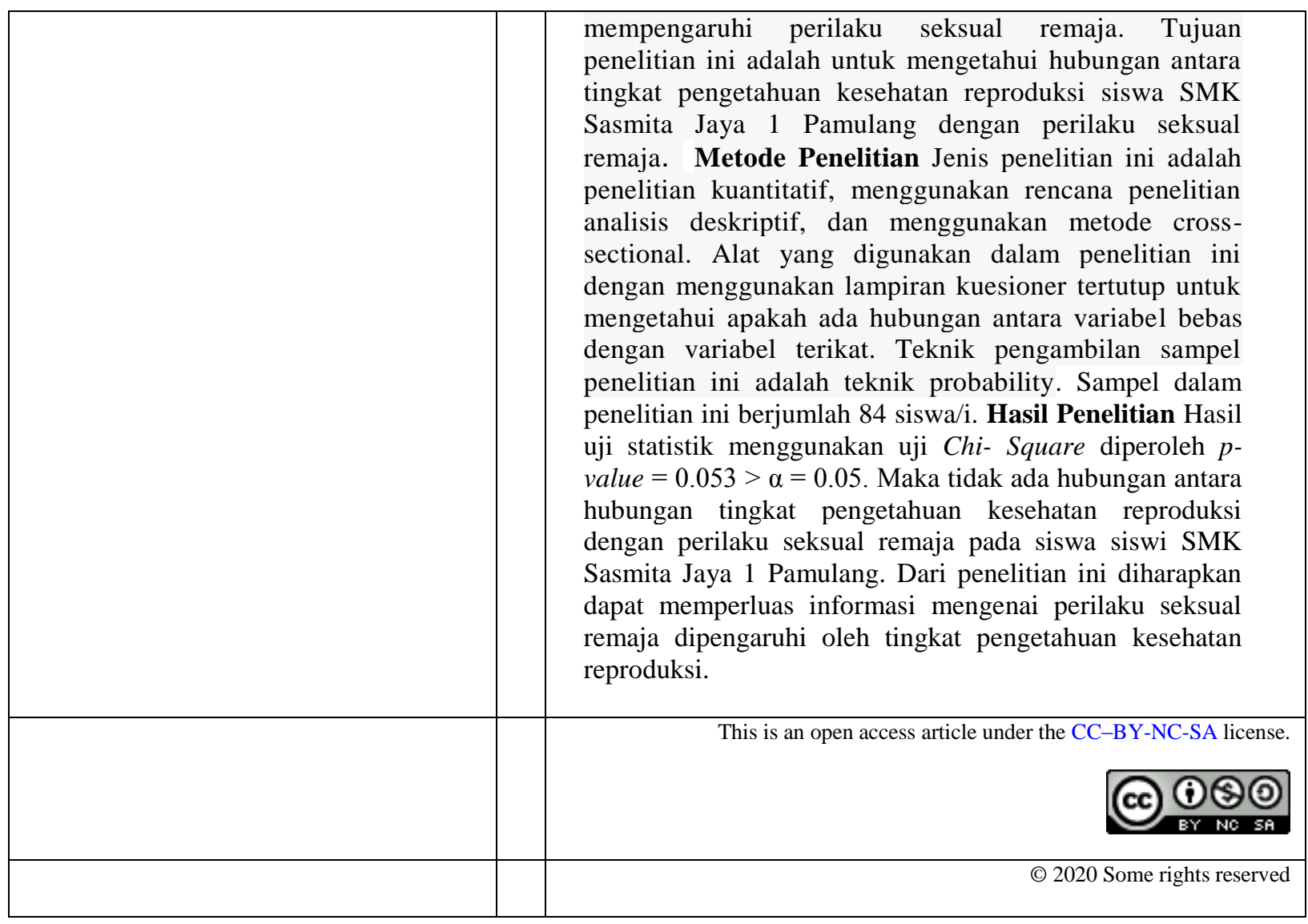




\section{PENDAHULUAN}

World Health Organization (WHO) menyatakan kesehatan produksi ialah keadaan sehat secara fisik terlihat dari kondisi tubuhnya, secara mental bisa terlihat dari psikis dan jiwanya dan secara sosial yang utuh, masyarakat yang utuh tidak hanya terbebas dari berbagai penyakit atau kecacatan dalam segala aspek yang berkaitan dengan sistem reproduksi, fungsi dan prosesnya (Rejeki, 2008).

Masa remaja ialah masa perkembangan antara batas transisi dari masa kanak-kanak hingga dewasa dibagi menjadi 2 bagian menurut World Health Organization (WHO), diantaranya yaitu remaja awal dengan rentan usia 10-14 tahun dan remaja akhir dengan rentan usia 15-20 tahun. Batasan usia remaja Indonesia yaitu berusia sekitar 11-24 tahun dan belum menikah (Sarwono, 2011).

Seksualitas akan mengalami perubahan, hal ini seiring dengan semua individu yang terus tumbuh dan berkembang (Perry\&Potter, 2010). Setiap proses perkembangannya mampu memberikan perubahan pada fungsi seksual dan juga perannya dalam hubungan seksual. Masa remaja bisa juga di katakan ada lebih banyak periode ketika individu mulai mencari orientasi seksual primer daripada periode lain dalam perkembangan manusia.
Perilaku seksual yang biasa dilakukan oleh remaja dapat menimbulkan berbagai dampak negatif. Beberapa contoh efek psikologis negatif termasuk kemarahan, ketakutan, kecemasan, depresi, harga diri rendah, perasaan bersalah dan bersalah. Ada juga beberapa pengaruh sosial, seperti dikucilkan oleh masyarakat, ibu hamil yang menjadi hamil akibat perubahan peran ibu putus sekolah, dan tekanan dari masyarakat, mereka bisa mengkritisi dan menolak keadaan tersebut. Selain itu, jika dilihat dari segi fisiologis ini juga dapat menyebabkan terjadinya kehamilan yang tidak diinginkan, yang dapat menyebabkan aborsi. Dari segi kondisi fisik tubuh juga terlihat dampak negatif lainnya yakni perkembangan penyakti menular seksual, HIV atau AIDS (Sarwono, 2011).

Berdasarkan sensus 2010, jumlah penduduk Indonesia saat itu adalah 237,6 juta jiwa. Diantara remaja, terdapat 63,4 juta orang, terdiri dari $3.216 .443,6$ juta $(50,70 \%)$ laki-laki dan $31.279 .012(49,30 \%)$ perempuan. Populasi kaum muda akan menjadi ini akan berdampak besar pada pertumbuhan penduduk di masa depan. Mayoritas penduduk remaja masih memerlukan perhatian khusus, karena 
remaja masih dalam usia sekolah, dan pada masa aktif secara seksual, usia kerja juga telah memasuki usia reproduktif. Kencan yang tidak sehat, sehingga bisa menimbulkan dan mengarah pada hal yang tidak diinginkan yaitu adaya hubungan seks bebas pranikah (Israwati, 2013).

\section{METODE}

Pada penelitian akan digunakan metode deskriptif analitik yang dilakukan dengan menggunakan metode Cross Sectional, yaitu penelitian yang di lakukan melalui pendekatan, bisa juga melalui observasi atau juga dengan kumpulkan data satu per satu (metode titik-waktu). Lokasi yang dipilih dalam melakukan penelitian ini yaitu berlokasi di SMK Sasmita Jaya 1 Pamulang. Penelitian dilakukan mulai April 2020 hingga Mei 2020.

Populasi penelitian ini yaitu jumlah dari seluruh siswa/i kelas $\mathrm{X}$ peminatan Multimedia di SMK Sasmita Jaya 1 Pamulang yang berjumlah 123 siswa/i. Jumlah Sampel yang akan diteliti diperoleh dengan perhitungan dengan menggunakan rumus Lemeshow, dan pengujian sampel memiliki selisih 2 proporsi yang di gunakan melalui aplikasi softwere (Lemeshow, 1997). Penelitian ini akan mengambil sampel yang berjumlah
84 responden dari jumlah popolasi, ada sebanyak 123 responden yang terdiri dari 4 kelas. Teknik pengambilan sampel dalam penelitian ini adalah dengan menggunakan "probability sampling" yang dapat memberikan peluang yang sama bagi setiap populasi sebagai sampel (Sugiono, 2018).

Dalam penelitian ini Instrument yang akan digunakan terdiri dari kuesioner pertanyaan berupa google from dengan 20 pertanyaan untuk variabel independent dan 13 pertanyaan variabel dependen. Analisa Univariat bertujuan untuk menjelaskan karateristik dari variabel Independent (Tingkat pengetahuan kesehatan reproduksi) dan variabel terikat (perilaku seksual remaja). Analisis bivariat dilakukan pada dua variabel terkait atau terkait. Gunakan uji chisquare dengan keyakinan 95\%, gunakan analisis ini melihat apakah ada hubungan antara kedua variabel.

\section{HASIL}

Tabel 1. Distribusi Frekuensi Responden Berdasarkan Usia di SMK Sasmita Jaya 1 Pamulang $(n=84)$

\begin{tabular}{ccc}
\hline $\begin{array}{c}\text { Usia } \\
\text { Responden }\end{array}$ & Jumlah & Persentase \\
\hline 15 Tahun & 13 & $15.5 \%$ \\
\hline 16 Tahun & 50 & $59.5 \%$ \\
\hline 17 Tahun & 14 & $16.7 \%$ \\
\hline 18 Tahun & 7 & $8.3 \%$ \\
\hline Total & 84 & $100 \%$ \\
\hline
\end{tabular}

Sumber : Data Primer, 2020 
Berdasarkan Tabel 1. Perilaku Seksual dari sebanyak 84 responden didapatkan hasil sebagian besar 69 responden memiliki perilaku seksual Baik dan sebagian kecil 15 responden (17.9\%) memiliki perilaku seksual yang Kurang baik.

Tabel 2. Distribusi Frekuensi Responden Berdasarkan Jenis Kelamin di SMK Sasmita Jaya 1 Pamulang $(n=84)$

\begin{tabular}{ccc}
\hline $\begin{array}{c}\text { Jenis } \\
\text { Kelamin }\end{array}$ & $\begin{array}{c}\text { Jumla } \\
\mathrm{h}\end{array}$ & Persentase \\
\hline Laki-laki & 65 & $77.4 \%$ \\
\hline Perempuan & 19 & $22.6 \%$ \\
\hline Total & 84 & $100 \%$ \\
\hline
\end{tabular}

Sumber : Data Primer, 2020

Berdasarkan Tabel 2 mengenai responden berdasarkan Jenis Kelamin yaitu dari 84 responden didapatkan hasil sebagian besar 65 reponden $(77.4 \%)$ berjenis kelamin laki-laki dan sebagian kecil 19 reponden $(22.6 \%)$ berjenis kelamin perempuan.

Tabel 3. Distribusi Frekuensi Responden Berdasarkan Tingkat Pengetahuan di SMK Sasmita Jaya 1 Pamulang $(\mathrm{n}=84)$

\begin{tabular}{ccc}
$(\mathrm{n}=84)$ & & \\
\hline Tingkat & Jumlah & Persentase \\
Pengetahuan & &
\end{tabular}

\begin{tabular}{ccc}
\hline Baik & 58 & $69 \%$ \\
\hline Cukup & 26 & $31 \%$ \\
\hline Total & 84 & $100 \%$ \\
\hline
\end{tabular}

Sumber : Data Primer, 2020

$\begin{array}{lll}\text { Berdasarkan } & \text { Tabel } 3, & \text { Tingkat } \\ \text { Pengetahuan } & \text { tentang } & \text { Kesehatan }\end{array}$

Reproduksi dari sebanyak 84 responden didapatkan hasil lebih dari setengahnya 58 responden (69\%) memiliki pengetahuan Baik dan hampir setengahnya 26 responden $(31 \%)$ memiliki pengetahuan Cukup mengenai kesehatan reproduksi.

Tabel 4. Distribusi Frekuensi Responden Berdasarkan Perilaku Seksual di SMK Sasmita Jaya 1 Pamulang $(\mathrm{n}=84)$

\begin{tabular}{ccc}
\hline $\begin{array}{c}\text { Perilaku } \\
\text { Seksual }\end{array}$ & Jumlah & Persentase \\
\hline Baik & 58 & $69 \%$ \\
\hline Kurang Baik & 26 & $31 \%$ \\
\hline Total & 84 & $100 \%$
\end{tabular}

Sumber : Data Primer, 2020

Berdasarkan Tabel 1.4. Perilaku Seksual dari sebanyak 84 responden didapatkan hasil sebagian besar 69 responden $(82.1 \%)$ memiliki perilaku seksual Baik dan sebagian kecil 15 responden (17.9\%) memiliki perilaku seksual yang Kurang baik.

Tabel 5. Analisis Hubungan Tingkat Pengetahuan Kesehatan Reproduksi dengan Perilaku Seksual remaja di SMK Sasmita Jaya 1 Pamulang $(n=84)$

\begin{tabular}{|c|c|c|c|c|c|c|c|}
\hline \multirow{3}{*}{$\begin{array}{l}\text { Pengetahu- } \\
\text { an }\end{array}$} & \multicolumn{4}{|c|}{ Perilaku Seksual } & \multicolumn{2}{|c|}{ Total } & \multirow{3}{*}{$\begin{array}{c}\mathrm{P}- \\
\text { Value }\end{array}$} \\
\hline & \multicolumn{2}{|c|}{ Baik } & \multicolumn{2}{|c|}{$\begin{array}{c}\text { Kurang } \\
\text { baik }\end{array}$} & & & \\
\hline & $\mathrm{N}$ & $\%$ & $\mathrm{~N}$ & $\%$ & $\mathrm{~N}$ & $\%$ & \\
\hline Baik & 44 & 75.9 & 14 & 2.1 & 58 & 100 & 0.053 \\
\hline Cukup & 25 & 96.2 & 1 & 3.8 & 26 & 100 & \\
\hline Total & 69 & 82.1 & 15 & 17.9 & 84 & 100 & \\
\hline
\end{tabular}




\section{PEMBAHASAN}

Berdasarkan tabel 5 yaitu analisis dari hubungan antara pengetahuan kesehatan reproduksi dengan perilaku seksual remaja siswa/i kelas X jurusam Multimedia di SMK Sasmita Jaya 1 Pamulang dengan 84 responden. Hasil analisis yang memperoleh pengetahuan yang baik dengan perilaku seksual baik sebagian besar 44 responden $(75.9 \%)$ dan hampir tidak ada 14 responden (2.1\%) yang memiliki pengetahuan baik dengan perilaku seksual kurang baik. Sedangkan untuk reponden yang pengetahuan cukup dengan perilaku seksual baik seluruhnya ada 25 responden $(96.2 \%)$ dan hampir tidak ada 1 responden $(3.8 \%)$ dan yang memiliki pengetahuan cukup dengan perilaku seksual kurang baik

Berdasarkan dari hasil analisis menggunakan rumus chi-square untuk mendapatkan analisis hubungan antara hasil uji statistik dengan tingkat pengetahuan kesehatan reproduksi dengan perilaku seksual remaja diperoleh nilai $p$-value $=$ $0.053>\alpha=0.05$. Maka $\mathrm{H}_{\mathrm{a}}$ ditolak itu bisa disimpulkan yaitu tidak ada hubungan antar tingkat pengetahuan kesehatan reproduksi dengan perilaku seksual remaja pada siswa/i kelas $\mathrm{X}$ jurusan Multimedia di SMK Sasmita Jaya 1 Pamulang.

\section{Usia}

Berdasarkan tabel 1.1 distribusi frekuensi responden berdasarkan umur sebanyak 84 responden didapatkan hasil lebih dari setengahnya 50 responden $(59.5 \%)$ berusia 16 tahun.

Menurut Janiwarty pada tahun 2013, remaja yang berusia 15-18 tahun merupakan remaja usia tengah, dimana masa remaja usia tengah ini ingin mandapatkan status yang bebas bisa menentukan sikap, pendapat dan keinginan, dan juga pola pergaulannya yang sudah mengarah pada heteroseksualnya.

Hasil penelitian ini sesuai dengan Niniek dan Hari pada tahun 2010 yang hal ini menunjukkan bahwa pada remaja usia 15-24 ada hubungan yang signifikan antara perilaku seksual pertama dan pengetahuan kesehatan reproduksi . Hal ini dapat dijelaskan dengan perilaku dan reproduksi remaja (seperti remaja), dari kondisi fisik masa kanak-kanak. Terlihat bahwa periode ini terlihat secara fisik, dari masa kanak-kanak hingga dewasa, terlihat baik secara psikologis maupun sosial. 


\section{Jenis Kelamin}

Berdasarkan tabel 1.2 yaitu mengenai distribusi frekuensi responden berdasarkan Jenis Kelamin dari 84 responden didapatkan hasil sebagian besar 65 reponden (77.4\%) berjenis kelamin laki-laki.

Menurut Santrock pada tahun 2011, pada remaja laki-laki lebih aktif secara seksual dibandingkan perempuan, hal ini disebabkan adanya perbedaan sosial dalam hubungan seksual antara lakilaki dan perempuan.

Penelitian ini sejalan dengan Mahmudah dan Suparmi pada tahun 2016, yang mengatakan remaja lakilaki itu berisiko lebih tinggi dalam melakukan perilaku seksual. Perkembangan seksual remaja dipengaruhi oleh faktor bio-psikososial secara seimbang. Secara biologis, laki-laki kadar hormon testosteron yang tinggi jika dibandingkan perempuan. Hormon ini berperan secara langsung terhadap dorongan seks pada laki-laki.

\section{Tingkat Pengetahuan}

Berdasarkan tabel 1.3 distribusi frekuensi responden berdasarkan Tingkat Pengetahuan tentang Kesehatan Reproduksi dari sebanyak 84 responden didapatkan hasil lebih dari setengahnya 58 responden $(69 \%)$ memiliki pengetahuan baik.

Menurut Notoatmodjo tahun 2014, pengetahuan merupakan faktor dominan, Ini sangat penting untuk pembentukan tingkah laku seseorang. Pengetahuan seseorang tentang suatu objek juga mengandung dua aspek, yaitu aspek negatif dan aspek positif. Kedua aspek ini pada akhirnya menentukan sikap seseorang terhadap objek tertentu. Pengetahuan mungkin diperlukan sebelum melakukan tindakan tertentu, tetapi kecuali orang tersebut memiliki motivasi yang kuat untuk melakukan tindakan berdasarkan pengetahuannya sendiri, perilaku yang diinginkan belum tentu terjadi.

Hasil penelitian ini sejalan dengan Sari dkk pada tahun 2014 di Bandar Lampung yang menyatakan bahwa pengetahuan tidak berpengaruh secara signifikan terhadap perilaku seksual pranikah.

\section{Perilaku Seksual Remaja}

Berdasarkan tabel 1.4 distribusi frekuensi responden berdasarkan Perilaku Seksual dari sebanyak 84 responden didapatkan hasil sebagian besar 69 responden $(82.1 \%)$ memiliki perilaku seksual baik.

Menururt Al-Mighwar pada tahun 2011, derajat perubahan sikap dan perilaku pada masa remaja mirip 
dengan laju perubahan fisik. Pubertas awal, saat tubuh berubah, tubuh berlangsung sangat cepat, perubahan tingkah laku dan sikap juga terjadi dengan cepat. Apalagi jika kurangi perubahan fisik, lalu ubah sikap dan perilaku akan berkurang.

Menurut penelitian yang dilakukan oleh Pinandari pada tahun 2015, menyatakan bahwa penerima informasi tentang seksualitas yang tidak lengkap dan jelas akan berpeluang semakin luas untuk melakukan hubungan seksual dimasa dini.

\section{Tingkat Pengetahuan Kesehatan}

\section{Reproduksi dengan Perilaku Seksual}

\section{Remaja}

Berdasarkan tabel 1.5 yaitu analisis hubungan tingkat pengetahuan kesehatan reproduksi siswa kelas $\mathrm{X}$ dengan perilaku seksual remaja dengan 84 responden. Hasil analisis diperoleh pengetahuan yang baik dengan perilaku seksual baik sebagian besar 44 responden (75.9\%) dan hampir tidak ada 14 responden (21\%) memiliki pengetahuan seks yang bagus.

Berdasarkan hasil analisis dengan menggunakan rumus chi-square didapatkan hasil uji statistik untuk menganalisis hubungan antara tingkat pengetahuan kesehatan reproduksi dengan perilaku seksual remaja adalah $\mathrm{p}$ value $=0,053>\alpha=0,05$. Karena Ha ditolak, dapat disimpulkan bahwa tidak ada hubungan antara tingkat pengetahuan kesehatan reproduksi siswa SMK Sasmita Jaya I Pmulang jurusan multimedia $\mathrm{X}$ dengan perilaku seksual.

Menurut Syamsulhuda pada tahun 2010, faktor lainya yang dapat juga memicu dalam perilaku seksual yaitu sikap dan efikasi diri merupakan faktor penting yang berpengaruh terhadap perilaku seksual remaja. Remaja yang memiliki pengetahuan baik tanpa memiliki sikap dan efikasi yang baik dapat terjerumus kedalam perilaku seksual yang kurang baik. Hal ini dapat disebabkan karena pendidikan terhadap kesehtan reproduksi yang disampaikan tanpa disertai dengan penanaman sikap dan nilai-nilai, sehingga tidak akan berperngaruh banyak terhadap perilaku remaja.

Hal ini juga sejalan dengan penelitian yang dilakukan olah Miftakhul Huda Fadhlullah pada tahun 2019 tentang Hubungan Tingkat Pengetahuan Kesehatan Reproduksi SMA dan SMK Dengan Perilaku Seksual Remaja yang berada di Kecamatan Cangkringan. Dengan jumlah sampel 109 siswa dengan menggunakan rancangan penampang 
dilengkapi dengan metode kuantitatif dan kualitatif. Hasil uji hipotesis chi-square diperoleh $\mathrm{p}$-value $=0,214>\alpha=0,05$ yang menunjukkan bahwa tidak ada hubungan yang signifikan antara pengetahuan kesehatan reproduksi dengan perilaku seksual remaja.

Berdasarkan hasil analisis diatas peneliti ini menyimpulkan bahwa remaja, mereka yang berpengetahuan luas mungkin melakukan hubungan seks yang buruk, begitu pula dengan remaja yang memiliki pengetahuan yang cukup bisa saja berhubungan seks yang baik. Semakin rendah pemahaman remaja tentang kesehatan reproduksi, meskipun pengetahuan kesehatan reproduksi semakin tinggi, namun perilaku seksual mereka semakin buruk.sudah tinggi namun tindakan perilaku hidup sehatnya masih cukup rendah.

Informasi mengenai seks tidak lengkap, pada umumnya remaja belum sepenuhnya memahami masalah seksual melalui informasi yang diperoleh dari media massa atau juga orang tuanya.

\section{KESIMPULAN}

1. Teridentifikasi siswa-siswi kelas $\mathrm{X}$ jurusan Multimedia di SMK Sasmita Jaya 1 Pamulang, bahwa dari 84 siswa/i yang dijadikan sampel lebih dari setengahnya berusia 16 tahun yaitu sebanyak $59.5 \%$ dan sebagian besar berjenis kelamin Laki-laki yaitu sebanyak $77.4 \%$.

2. Teridentifikasi siswa-siswi kelas $X$ jurusan Multimedia di SMK Sasmita Jaya 1 Pamulang, dari 84 siswa/i yang dijadikan sampel lebih dari setengahnya berpengetahuan baik yaitu sebanyak $69 \%$.

3. Teridentifikasi siswa-siswi kelas $\mathrm{X}$ jurusan Multimedia di SMK Sasmita Jaya 1 Pamulang, dari 84 siswa/i yang dijadikan sampel sebagian besar berperilaku baik yaitu sebanyak $82.1 \%$.

4. Teridentifikasi Hasil penelitian yang dilakukan menunjukkan bahwa tidak ada hubungan antara pengetahuan kesehatan reproduksi siswa dengan perilaku seksual remaja pada siswa SMK Sasmita Jaya I Multimedia X Pamulang didapatkan bahwa nilai $\mathrm{p}$ value $=0.053>$ nilai $\alpha=0.05$.

\section{DAFTAR PUSTAKA}

Damayanti, Rahmi. 2014. Hubungan Tingkat Pengetahuan Kesehatan Reproduksi Remaja Dengan Sikap seks Pranikah Pada Mahasiswa Semester 4 Program Studi Di Bidan Pendidik STIKes Aisyiyah Yogyakart. http://digilib.unisayogya.ac.id $\angle 1185 / 1$

$\not$ rahmi\%20damayanti 201310 104358 naskah\%20publikasi. pdf diunduh pada tanggal 30 Januari 2020 pukul 10.42 WIB. 
Hani, Fauziah. 2019. Hubungan Pengetahuan Dan Persepsi Tentang Seksualitas Pada Remaja Dengan Perilaku Seks Pada Siswa Kelas XI Jurusan Akuntansi di SMK Sasmita Jaya 1 Pamulang.

Istiqomah, Nita. 2016. Pengaruh Pengetahuan, Kontrol Diri Terhadap Perilaku Seksual Pranikah Di Kalangan Remaja SMK Di Surabaya. Jurnal Biometrika dan

Kependudukan.http://ejournal.unair.ac.id/index.php/JB $\underline{\text { K/arti }}$ cle/view/5832 diunduh pada tanggal 20 Januari 2020 pukul 18.22 WIB.

Janiwarty, B. 2013. Pendidikan Psikologi untuk Bidan - Suatu Teori dan Terapannya. Yogyakarta: Andi Offset, Raphs Pubblishing.

Kumalasari, Desi. 2014. Hubungan Pengetahuan Dan Sikap Dengan Perilaku Seksual Pada Siswa SMK. Program Studi Kebidanan, STIKes Aisyah Pringseweu Lampung. https://aisyah.journalpress.id/index. $\mathrm{ph} \mathrm{p} / \mathrm{jika} /$ article/view/DK diunduh pada tanggal 20 Januari 2020 pukul 16.12 WIB.

Mahmudah. 2016. Faktor-faktor yang berhubungan dengan perilaku seksual remaja di kota padang, jurnal kesehatan andalas. http://jurnal.fk.unand.ac.id/index.ph $\mathrm{p} / \mathrm{jka} /$ article/view/538 diunduh pada tanggal 30 Mei 2020 pukul 19.55 WIB.

Notoatmodjo. 2014. Ilmu Perilaku Kesehatan. Jakarta: Rineka Cipta

$\begin{array}{ccr}\text { Pratiwi dan } & \text { Hari. 2010. } & \text { Analisis } \\ \text { Hubungan } & \text { Perilaku } & \text { Seks } \\ \text { Pertamakali } & \text { Tidak Aman } & \text { Pada }\end{array}$

Remaja Usia 15-24 Tahun Dan Kesehatan Reproduksi. Buletin Penelitian Sistem Kesehatan. https://www.neliti.com/publications 12 1310/analisis-hubungan-perilakuseks-pertamakali-tidak-aman-padaremaja-usia-1524-tah diunduh pada tanggal 30 Mei 2020 pukul 20.02 WIB.

Rina, Nelva, dkk. 2013. Faktor-faktor yang mempengaruhi sikap remaja terhadap seks pranikah. Program studi Ilmu Keperawatan. Universitas Riau. https://www.neliti.com/publications $11 \quad$ 89186/faktor-faktor-yangmempengaruhi-sikap-remajaterhadap-seks-pranikah diunduh pada

Sarwono, Prawirhardjo. 2011. Psikologi Remaja. Jakarta: Rajawali Pers.

Sugiyono. 2018. Metode Penelitian (Pendekatan Kuantitatif, Kualitatif dan R\&D). Bandung: Alfabeta.

Wulandari, Sri. 2015.

Hubungan Pengetahuan, Sikap Dan Perilaku Penyakit Menular Seksual (PMS) dan HIV/AIDS Dengan Pemanfaatan Pusat Informasi Konseling Remaja (PIK) Pada Remaja SMKN Tandun Kabupaten Rokan Hulu, Jurnal Maternity dan Neonatal. http://e-

journal.upp.ac.id/index.php/akbd /arti cle/view/1086 diunduh pada tanggal 30 Januari 2020 pukul 20.25 WIB. 